\title{
Oxidative stress in viral HEPATITIS B and C
}

Original Research Article

\author{
Emine Siber Namıduru ${ }^{1 *}$, Mustafa Namıduru ${ }^{2}$ \\ ${ }^{1}$ University of Gaziantep, Faculty of Health Sciences, Department of Nutrition and Dietetics, Gaziantep, Turkey \\ ${ }^{2}$ University of Gaziantep, Faculty of Medicine, Department of Infectious Disease, Gaziantep, Turkey
}

Received: 15-09-2019 / Revised: 20-11-2019 / Accepted: 27-11-2019

\begin{abstract}
Chronic infections are controlled by a variety of mechanisms, including the induction of oxidative stress. Some viral infections reduce the ability to defend against pro-oxidant strains, especially in liver cells. Oxidative and nitrosative stress can damage cellular membranes, disrupt mitochondrial function, alter gene expression, promote the apoptosis and necrosis of hepatocytes, and increase fibrosis in diverse acute andchronic liver diseases. Chronic infections caused by the hepatotropic viruses hepatitis B virus and hepatitis C virus are the main risk factors for the development of hepatocellular carcinoma. Despite the obvious clinical importance of virus-associated hepatocellular carcinoma, the underlying molecular mechanisms are not fully understood. Oxidative stress plays an important role in carcinogenesis, especially with DNA lesions caused by oxidative damage additionally there are strongly linked to the development of many cancers, including hepatocellular carcinoma.Many studies have shown that both hepatitis $B$ virus and hepatitis $C$ virus cause hepatic oxidative stress.
\end{abstract}

Key words: Oxidative stress, viral hepatitis B, viral hepatitis C

(0) The Author(s). 2019 Open Access. This work is licensed under a Creative Commons Attribution. The full terms of this license are available at our website and incorporate the Creative Commons Attribution. https://creativecommons.org/licenses/by/4.0/

\section{INTRODUCTION}

Oxidative stress (OS) is triggered when the concentration of oxygen species in the extracellular or intracellular environment exceeds antioxidant defenses. It can also be described as irregular redox signaling and control. ${ }^{[1]}$ Normally in all of our body cells have a balance in the oxidation/reduction system that is crucial to the cells' survival. If this balance breaks down for any reason, either the oxidant levels increase or the antioxidant levels decrease, which is termed a state of "OS".It is harmful to the cell. The structure of macromolecules in the cell, such as DNA, lipid, protein breaks down in the oxidative stress conditions. ${ }^{[2,3]} \mathrm{OS}$ causes oxidative damage to the structure of biomolecules, thereby altering their physiological functions. To prevent the harmful effects of reactive oxygen species (ROS), biological systems have developed a variety of detoxification mechanisms using a large number of small molecules, peptides and enzymes, like glutathione (GSH) or superoxide dismutase (SOD), respectively.

\section{*Corresponding Author}

Emine Siber Namiduru

University of Gaziantep, Faculty of Health Sciences, Department of Nutrition and Dietetics, Gaziantep, Turkey.

E-mail: enamiduru@gmail.com
OS also triggers the nitrosative stress caused by reactive nitrogen species (RNS) and thus results in cellular signalling deterioration and cellular damage. The results of the studies reported that oxidative and nitrosative DNA damage was seen in carcinogenesis areas, independent of the etiology of the disease. ${ }^{[4]}$ ROS and RNS are produced by mitochondrial electron transport or by other enzyme systems containing many oxido reductases (such as NADPH oxidase which is critical for the bactericidal action of phagocytes) in all cells types, including hepatocytes. ${ }^{[5]}$ Researchers have reported that oxidative stress may lead to an increase in calcium leakage in the endoplasmic reticulum(ER) lumen and that the same occurs in ER stress. Increase in calcium concentration in cytosol also increases mitochondrial ROS production. ${ }^{[1]}$ Many OS related illnesses have been reported by Sies ${ }^{[6]}$ in 1985 . Some of the most studied diseases are neurodegenerative diseases(Alzheimer, Parkinson, and others). [2,7,8] cellular aging [9], cardiovascular diseases (hyper cholesterolaemia, heart failure, hypertension, myocardial infarction, ischemia/reperfusion injury, and atherosclerosis), and pathologies involving chronic inflammation. ${ }^{[10,11]}$ As a result, OS is now seen as a major suspect in the pathogenesis of a wide spectrum of disease and cancer. Chronic infections caused by 
factors such as hepatitis B virus (HBV) and hepatitis C virus $(\mathrm{HCV})$ are the main risk factors for the onset and progression of hepatocellular carcinoma (HCC). [12] Over the world, up to $80 \%$ of $\mathrm{HCC}$ can be attributed to HBV or HCV infection. The results of the study indicate that although the viral proteins themselves indicate that they contribute directly to tumor formation, the underlying mechanisms remain uncertain. ${ }^{[13]}$ There are increasing evidence that the viral proteins of $\mathrm{HBV}$ and HCV may themselves contribute to a state of chronic OS in infected hepatocytes. OS has great importance for both infectious diseases and non- infectious diseases. Studies of redox biology have provided a better understanding of oxidative stress. ${ }^{[14]}$ The reactive molecules tend to nonspecifically oxidize the basic biological macromolecules in its environment and thus cause acute cell damage or cause gradual deterioration of important cell functions. Thus, $\mathrm{O}_{2}$ is the basis of aerobic metabolism and ROS production, a consequence of aerobic metabolism, is often associated with deleterious effects. In addition, ROS, RNS, and reactive sulfur species can promote pathogenesis through cell signaling. By modifying or participating in different signal paths these reactive species can modulate gene expression, cell adhesion, cell metabolism, cell cycle and cell death, thus contributing to pathogenesis. For example, OS may induce the proliferation of hepatic stellate cells, TGF- $\beta$ and collagen synthesis. This likely plays an important role in the development of liver fibrosis associated with the hepatitis virus infection. Furthermore, OS in hepatitis patients may contribute to the development of hepatic steatosis and the progression of fibrosis. The hepatic metabolism of biological toxins and medicinal agents is associated with impaired hepatocyte biochemistry and increased ROS and free radicals. It has been reported that redox imbalance and OS, causes subclinical anicteric hepatitis (acute, recurrent, or chronic), necroinflammatory hepatitis, cirrhosis and carcinoma. ${ }^{[15-17]}$ The aim of this review was to clarify the role of OSin hepatitis B and C so that its results could contribute to a better understanding of these diseases and its improved treatment or cure.

\section{Hepatitis B}

HBV is a DNA hepa DNA virus with a 25- to 180-day incubation period. It is estimated that $5 \%$ of the world population have hepatitis B. Although it has been 50 years since the discovery of the Australian Antigen by, Professor Baruch Samuel Blumberg, the hepatitis B virus still affects approximately 350 million individuals around the world and is responsible for the deaths of about one million people annually. It has been that great progress in the prevention, diagnosis, and treatment of hepatitis B in the past few decades; however, there is not enough evidence to prevent or eliminate the disease. In 1983, the production of the first hepatitis B vaccine was promising in controlling and preventing the disease in the control of the disease. In the following years, with the production and development of the first antiviral drugs, this point of view became even stronger. ${ }^{[18,19]}$ ROS(such as superoxide, hydrogen peroxide, singlet oxygen, and hydroxyl radicals)and RNS, which are induced by various endogenous (e.g., mitochondria, enzymes, etc.) and exogenous (e.g., chemicals, tobacco, ultraviolet rays, etc.) factors lead to widespread oxidative damage to different biomolecules including lipids, proteins, and DNA. ${ }^{[2]}$ ROS and RNS are highly unstable and shortlived species; although these molecules have been great cellular signaling, they are particularly difficult to direct measure. Therefore, to detect their oxidation status, we can measure indirectly, which proteins, lipids, and DNA are damaged by the ROS/RNS.

\section{Lipid peroxidation}

The lipids in cell membranes produce many of the reactive products such as malondialdehyde (MDA) upon oxidative stress. Many studies have detected that the presence of lipid peroxidation in hepatitis B infection. ${ }^{[18]}$ MDA has been evaluated as a marker of lipid peroxidation product in these studies.MDA changes other molecules to produce novel oxidationspecific epitopes that takes the attention and inflammatory reaction of the innate immune system. It has been found that MDA is also to attract an immune system protein called complement factor $\mathrm{H}$. This factor stops the uptake of MDA-modified proteins by macrophages after binding to MDA. This is demonstrated by neutralizing the inflammatory effects of MDA in the mouse model. ${ }^{[20]}$ It was founded significantly higher in patients with hepatitis B infection compared to healthy individuals. ${ }^{[21,22]} \mathrm{We}$ also found MDA values consistent with these outcomes in the HBV patient group. ${ }^{[23]}$ Moreover, in our study MDA levels were not correlated with biochemical parameters, necro-inflammatory activity, fibrosis score or viral load in subjects with CVH-B infection. Some studies have reported that a correlation between MDA levels and alanineaminotransferase (ALT) [21, 22, 24, 25], HBV-DNA ${ }^{[21,26]}$, total and direct bilirubin. ${ }^{[}$According to these results, lipid peroxidation and its products can be said to activate hepatic stellate cells and lead to active fibrogenesis. However, Severi et al. has been showed that although of HBV replication produced OS, 
it did not significantly affect lipid peroxidation product levels in their invitro model study. ${ }^{[28]}$ Previous studies in this field have generally assessed plasma and erythrocyte levels of lipid peroxidation products. In future studies, it would be more useful to investigate lipid peroxidation product concentrations in the hepatic tissue

\section{Protein Oxidation}

Increased oxidative stress can damage proteins with various mechanisms. Nitrotyrosine, Oxidases, protein hydroxides and carbonyl derivatives have been studied as protein oxidation products. Protein oxidative products are more stable and suitable markers than lipid oxidation of OS. In addition, protein oxidation byproducts can provide valuable clues about the origin and severity of oxidative stress.For example, nitrotyrosylresidues are produced by $\mathrm{HOCl}$ and indicate the presence of nitric oxide and superoxide or cholortyrosine residues in the presence of neutrophils

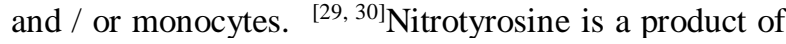
peroxynitrite mediated tyrosine nitration, which is an indication of increased peroxynitrite formation and nitrosative stress. Our study showed that no significant difference between the plasma nitrotyrosine levels of healthy individuals and chronic viral hepatitis B patients. ${ }^{[23]}$ However, one study performed by Meng et al. demonstrated a significant increase in the serum nitrotyrosine levels of patients with chronic hepatitis B.

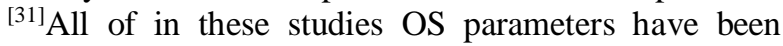
detected in samples sera or plasma. However, in viral liver patients, the plasma or serum levels may not reflect accumulation of nitrotyrosine in the hepatic tissue.In addition, it has been reported that intrahepatic nitrotyrosine accumulation is present in viral liver diseases, but not in non-viral diseases, and a statistically significant relationship is found between the amount of intrahepatic NTY and the severity of viral liver disease[32]. On the other hand in our study, it was detected that plasma NTY levels did not correlate with HAI, fibrosis score or viral load.Taşdelen et al has been performed that a significant carbonyl level increase was identified in chronic active andinactive hepatitis B patients compared with the controls. They also have been noted a mild to moderate correlation between HBV DNA and carbonyl levels, which may indicate that several degrees of OS occur in hepatitis B infection. ${ }^{[26]}$ In a study performed by Popadiuk et al has been detected significantly enhanced plasma carbonyl levels in children with chronic hepatitis B infection. ${ }^{[33]}$ Additionally increased plasmacarbonyls were also identified in patients with HBV-related HCC.

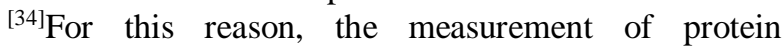

oxidation products is of great value. The increase in the level of each product may be a guide in elucidating the underlying pathogenesis of the disease. This is why protein oxidation needs to be studied further. There is no single method for measuring protein oxidation and a separate method is applied for each parameter.

\section{DNA oxidation}

OS can produce a various of DNA damage, which can lead to mutations and defects in genome structure. Olinski et al has been showed that 8-oxo-7, 8-dihydro2 '-deoxyguanine (8-oxo-dG) is the most suitable to be measured as an oxidative DNA marker. ${ }^{[35]}$ In a study done by Shimoda et al. reported an increased formation of 8-hydroxydeoxyguanosine $(8 \mathrm{OHdG})$ in chronic hepatitis patients livers. ${ }^{[36]}$ It has been found that an increase in the oxidative DNA damage in patients with CVHB as the disease progressed from the earlier to the later stages and eventually led to HCC. Hepatic oxo8dg levels were higher at advanced stages than from CVHB patients with no fibrosis ${ }^{[37]}$ Kitada et al. showed that chronic HBV patients had extensive DNA damage in liver tissues by $80 \mathrm{HDG}$ immunolabeling. [38] Urinary 8OHDG levels were also increased in patients with chronic hepatitis. ${ }^{[39]}$ The hepatic $80 \mathrm{HdG}$ levels from the tissue samples of CVHB indicated extensive DNA oxidation occurring in the liver,Additionally this hepatic $8 \mathrm{OHdG}$ reactivity was strongly correlated with ALT, AST, HBV-DNA titers, and age (respectively $\mathrm{r}=0.506,0.515,0.540$ and - 0.559) in CVHB patients [40]. Although the results of these studies indicate the presence of DNA oxidation and damage in $\mathrm{HBV}$, there is a need to work more focused on DNA oxidation.

\section{ROS-Producing Enzymes and ROS/RNS Production ROS/RNS Production}

ROS/RNS species, which originate from oxidative or nitrosative stress are highly unstable. So it is difficult to measure directly. There are a few study measured ROS/RNS species production in patient with HBV in the literature. A study by Bhargava et al. reported increased ROS levels in lymphocytes of chronic and occult hepatitis B patients. ${ }^{[41]}$ It has been reported that increased NO levels in CVHB. But Guler et al. did not find any significant differences compared to healthy controls. ${ }^{[42]}$ In addition Tsai et al indicated that there is a significant increase in superoxide anion radicals in HCC patients associated with HBV. ${ }^{[43]}$ Nagoev et al had been seen that this anions were increased also in the leukocytes of patients with CVHB. ${ }^{[44]} \mathrm{It}$ is 
important to disclose correlations between ROS / RNS production and hepatitis B disease activity.

\section{ROS-Producing Enzymes}

Multiple enzymes, including cytochrome P450, peroxisomal oxidases, cyclooxygenases, lipooxygenases, and the nicotinamide adenine dinucleotide phosphate (NADPH) oxidases, are associated with the formation of ROS.Such as NADPH oxidase (NOX family), myeloperoxidase (MPO) and xanthine oxidase enzymes can generate ROS/RNS species.Detection of the activities of these enzymes in hepatitis B patients will provide a better understanding of the role of oxidative and nitrosative stress in this infection. ${ }^{[45]}$ In the meantime, it should be noted that the enzymes that produce ROS are more important.

\section{Myeloperoxidase}

Myeloperoxidase (MPO) is a lysosomal heme protein that is abundant in granules of human inflammatory cells such as activated neutrophils, macrophages and monocytes. MPO acts as a master enzyme in the generation of a range of ROS by catalyzing the conversion of hydrogen peroxide $\left(\mathrm{H}_{2} \mathrm{O}_{2}\right)$ to species including ${ }^{\circ} \mathrm{OH}, \mathrm{ONOO}^{-}$, hypochlorous acid $(\mathrm{HOCl})$, and $\mathrm{NO}_{2}$. MPO-derived ROS can then modify lipids, lipoproteins and proteins.MPO enzyme activity is readily measurable, so it is one of the promising biomarkers of OS. ${ }^{[45]} \mathrm{We}$ have been seen that significantly decreased plasma MPO levels were in patients with hepatitis B when compared to healthy controls. However, this difference was not correlated with viral load, necroinflammatory activity or fibrosis score in the liver. ${ }^{[23]}$ A study by Tasdelen et al. revealed a significant decrease in the mean plasma MPO levels in HBV patients compatible with our result and this decrease was shown to have a significant negative correlation with the HBV DNA levels in both active and inactive hepatitis B patients. ${ }^{[26]}$ The plasma of hepatitis B patients was used in these studies and MPO levels in hepatic tissue samples were not measured.Considering the excessive amount of oxidation in patients with hepatitis $\mathrm{B}$, presumably very high levels of plasma MPO may be expected. Therefore, this unexpected result could probably be attributed to the site of sampling or cause the severity and progression of the viral disease. But there are also conflicting results in the literature. A group of investigators found a significant increase in plasma MPO activities in HBV-associated cirrhotic patients and found no significant difference between healthy controls and CHBV patients. There was also a positive correlation between plasma MPO activity and liver fibrosis. These results suggest that MPO plasma levels may be indicative of disease progression. Thus, plasma enzyme activity levels of patients may not increase significantly until cirrhosis occurs. Guler et al. detected that a significant increase in serum MPO activities was observed in chronic active and inactive hepatitis B compared to healthy controls. Enzyme activities have been also positively correlated with the patients' DNA and ALT levels. ${ }^{[42]}$ As a result, further extensive studies are needed to clarify the exact state of the MPO in hepatitis B.

\section{Hepatitis $B$ and Antioxidants}

Le Châtelier principle, one of the most important laws of chemistry, emphasizes that a system in balance will remain in balance as long as it is not disturbed. In normal physiological conditions, the human body provides its own balance by using oxidants and antioxidants. OS occurs when this balance is impaired by some environmental factors. OS is a disorder that leads to a potential cellular damage. Most cells can tolerate a mild degree of OS, because they have sufficient antioxidant defense capacity and repair systems, which recognize and remove molecules damaged by oxidation. It is known that OS is associated with more than over 100 diseases. ${ }^{\text {[47] Our }}$ antioxidant defense system consists of two synergistic compartments: endogenous antioxidants (e.g., superoxide dismutase, glutathione peroxidase, catalase, glutathione etc.) and exogenous antioxidants. It is reported that our immune system should be supplemented with exogenous antioxidants such as vitamin C, vitamin E and carotenoids. ${ }^{[48]}$ Detection of antioxidant status in hepatitis $\mathrm{B}$ and $\mathrm{a}$ better understanding of antioxidant supplementation therapy will guide the progression of the disease. There are many studies showing antioxidant status in CVHB patients. We showed that erythrocyte SOD, catalase, glutathione peroxidase activities, GSH and serum total antioxidant response levels were significantly lower in patients than in controls. Additionally, no significant correlation was found between these markers and viral load, necro-inflammation, and fibrosis of the liver in patients with chronic viral hepatitis. ${ }^{[49]} \mathrm{GSH}$ is synthesized in all types of eukaryotic cells and especially found in liver. It is considered as one of the most important anti-oxidants. There are a few studies in the literature that found reduced levels of GSH in erythrocytes of CVHB patients. ${ }^{[25,26,50,51]}$ Tasdelen et al has been also found that a negative correlation between HBV DNA and erythrocyte GSH levels ${ }^{[26]}$ Moreover Kundu et al noted a significant negative correlation ALT, AST, GGT, and ALP with erythrocytes glutathione levels in CVHB patients. ${ }^{[25]}$ Some researchers have reported increase levels of plasma GSH in acute hepatitis B patients. ${ }^{[51]}$ Because of this unexpected increase, there may be compensatory mechanisms seen at the beginning of a 
disease. It has been reported that despite the initial increase in plasma glutathione levels in acute hepatitis B patients, it began to fall as the disease became more severe and chronic. Also in patients with chronic hepatitis B and severe acute hepatitis B, erythrocyte GSH were decrease with plasma glutathione levels decrease simultaneously. ${ }^{[51]} \mathrm{We}$ and some researchers have been reported decreased levels of glutathione peroxidase $[26,49,52]$ while there was an increase in another study. It has been reported that low SOD and catalase activity and elevated lipid peroxidation levels in chronic B hepatitis patients indicate deficient antioxidant defense. ${ }^{[53]}$ The erythrocyte SOD activities of hepatitis B patients were lower than controls, and the results of these studies were compatible. ${ }^{[26,33,49]}$ But there are conflicting results regarding serum SOD activities. [31, 43, 54,55] Catalase, which is an important antioxidant enzyme, has been measured in both erythrocyte and serum levels. The results are not compatible ${ }^{[26,49,53,56]}$ The total antioxidant capacity parameter which with worked different methods (TAS, TAC) was found to been decreased in all hepatitis B patient groups. ${ }^{[21,49,57-59]}$ There was detected a decrease in the products of lipid peroxidation (as MDA levels) and an increase in the antioxidant enzymes, such as CuZnSOD and GSH-Px in HBV patients after treatment with interferon- $\alpha$ and lamivudine, compared with pretreatment. ${ }^{[22]}$ There may be factors causes of contradictory outcomes include methodology, sample size, statistical analysis, disease progression, control group difference, etc. However, these controversial outcomes are indicative of a complex OS process. More extensive studies will be needed to determine the role of different antioxidants in hepatitis $\mathrm{B}$.

\section{Hepatitis C}

The HCV infection is a major biomedical problem, with an incubation period of 11-150 days is transmitted primarily via infected blood more than 150 million humans infected worldwide, which accounts for approximately 3-4 million new cases of viral hepatitis each year. Differently from the other hepatitis viruses (A, B, and $\mathrm{E}$ ), more than $80 \%$ of $\mathrm{HCV}$ patients become chronic.It is known that chronic HCV infection is associated with liver inflammation (hepatitis), fibrosis, cirrhosis and hepatocellular carcinoma. ${ }^{[60]}$ Hence, HCV infection is the leading cause of liver transplantation worldwide. There is no effective vaccine against $\mathrm{HCV}$ and current treatments are only partially effective. Proper diagnosis of infected patients is essential for the effectiveness of the treatment. ${ }^{[61]}$ This was reported that $\mathrm{HCV}$ produces more ROS than other hepatitis viruses and patients with chronic hepatitis $\mathrm{C}$ have over $80 \%$ chances of developing chronic diseases as compared to patients of hepatitis A, B and E. [62] Hepatic OS, a prominent feature of chronic hepatitis $\mathrm{C}$ infection, is seen in a number of inflammatory liver diseases. [40] $\mathrm{HCV}$ infection is known to cause activation of the immune system and macrophages, and therefore ROS can be produced by blood cells. Cell damage caused by OS is known to play an important role in the pathophysiology of HCV. There are also studies showing that chronic $\mathrm{HCV}$ infection is caused by mitochondrial dysfunction and OS. ${ }^{[63]} \mathrm{OS}$ can also occur when $\mathrm{HCV}$ components are taken up by the liver kupffer cells. Active kupffer cells have been reported to contribute to the killing of hepatocytes by various mechanisms. These cells enhance not only the local production of cytokines such as TNF- $\alpha$ but also ROS production. ${ }^{[64]}$ However, the mechanisms by which Kupffer cells cause OS and liver damage are not fully understood. Damaged hepatocytes release ROS in the extracellular environment, leading to the activation of hepatic stellate cells.It is well known that the largest part of the ROS produced in the cells is derived from mitochondria. Mitochondria, which are the power plants of the cells, are the main targets of HCV virus. It was also detected that $\mathrm{HCV}$ produces ultrastructural changes in these organelles and causes oxidative damage and a reduction in mitochondrial DNA copy number, in both hepatocytes and lymphocytes of infected patients. ${ }^{[65]}$ In $\mathrm{HCV}$, increases in NADPH oxidase have been reported to increase ROS and RNS, which may lead to chronic inflammation in these patients. ${ }^{[15]}$ Although HCV core and other proteins primarily localizes to the ER, it also associates with mitochondria. Oxidative DNA damage increases chromosomal aberrations associated with cell transformation, and OS plays a role in the development of HCC associated with HCV. For example, increased ROS / RNS levels have been found to promote DNA damage and hepatocellular carcinoma development by increasing mutations in cellular genes. ${ }^{[66]}$ In animal modeling and culture systems studies, it has been observed that HCV- expressed proteins directly destroy the mitochondrial respiratory chain with overproduction of ROS. Thus the structure and function of mitochondria may change in infected hepatocytes. Thus, it is suggested that the mitochondria's structure and function may change of infected hepatocytes. ${ }^{[62]}$ The transcriptional and replication mechanisms of mitochondria are upregulated so that mitochondrial biogenesis increases with mitochondrial genome replication in OS conditions. In these damaged mitochondria can be inhibited by the electron transport chain, which can lead to ROS accumulation. ${ }^{[67]}$ Three mechanisms are known to contribute to $\mathrm{HCV}$-associated OS; These 
include (i) mitochondrial dysfunction; (ii) ER stress and (iii) immune cell-mediated oxidative bursts. The $\mathrm{HCV}$ core protein is known to be strong in this respect and and its expression is sufficient to produce OS. ${ }^{[68]} \mathrm{It}$ is reported that $\mathrm{HCV}$ replication induces OS. Oxidative stress is thought to be a clinical feature associated with hepatitis $\mathrm{C}$ infection, little is known about how the virus can survive in a highly oxidative environment. OS adaptation is predicted to be the key to the survival of the virus. ${ }^{[69]}$ There are some studies that use antioxidants in clinical trials in the treatment of $\mathrm{HCV}$ patients. ${ }^{[70-72]}$ Many different OS markers have been studied in hepatitis $\mathrm{C}$ patients, including lipid peroxidation products and oxidized protein and ROS/RNS producing enzymes. ${ }^{[23,73,74]}$

Some investigators have found that high levels of OS markers correlate with the severity of the disease in hepatitis C patients and that OS decreases after successful treatment. ${ }^{[73,75]}$

\section{Lipid peroxidation}

MDA release and hepatic damage by membrane lipid peroxidation were found to be induced by GSH depletion in HCV patients. De Maria et al have shown that (i) lipid oxidation occurs in chronic hepatitis C, (ii) oxidative damage has increased levels of MDA, and (iii) MDA levels correlate with disease activity.These results arein accordance with the findings of other investigators and our result. ${ }^{[23,76]} \mathrm{We}$ detected also that plasma MDA levels were significantly higher in the CVH-C patients than the controls $(\mathrm{p}<0.001)$. Additionally in patients with CVH-C, Spearman's correlationanalysis showed no significant correlation betweenplasma MDA, viral load ( HCV-RNA), fibrosis score and HAI ( $p>0.05$ ).Increased lipid peroxides may be chemotactic effect for neutrophils leading to increased inflammation, resulting in oxidantmediated injury in the liver.

\section{Protein and DNA Oxidation}

Lipid peroxidation/ advanced oxidation protein products and 8-hydroxy deoxyguanosine (8-OHdG) are biological molecules modified with ROS. These molecules were found at significantly higher levels in PBMCs in HCV patients compared to healthy controls. [76- ${ }^{79]}$ In CHC patient liver samples were detected a significant increase of $8-\mathrm{OHdG}$ levels. ${ }^{[38]}$ Recently, several mechanisms have been proposed that may contribute to the replacement of cell fate by forming ROS-induced apoptosis tumor occurrence in the animals. First, OS leads to DNA damage (including 8$\mathrm{OHdG}$ ) and accumulation of mutations.Liu et al reported that nitration of tyrosine, in both proteinbound form and free amino acid form, can readily occur in cells under oxidative/nitrative stress. ${ }^{[80]}$

\section{Nitrotyrosine}

Viral hepatitis has been found to be associated with an increased iNOS expression, and there is also a suspicious relationship with iNOS expression and disease severity. Increased iNOS expression increases the amount of RNS, which is associated with DNA damage, and NO plays a role in the development of HCC as DNA damage causes cancer development. García-Monzón et al demonstrated that the intrahepatic accumulation of NTY - a marker of peroxynitrite attack on cellular proteins - was positively related to the severity of liver damage in CVH. ${ }^{[32]}$ Recently a direct correlation has been documented between iNOS induction and hepatitis $\mathrm{C}$ virus ribonucleic acid (HCVRNA) titer and also hepatocyte nitrotyrosine, plasma nitrosothiols and histological severity of liver damage. Therefore, in addition to OS, it is thought that nitrosative stress may play a role in the pathogenesis of chronic viral hepatitis. ${ }^{[80]}$ In our study there were no statistically significant differences between the serum NTY levels of the patients with chronic HCV and the controls $(\mathrm{p}>0.05)$. In addition correlation analysis showed no significant correlation between plasma NTY with viral load (HCV-RNA), fibrosis score and HAI $(p>0.05)$.

\section{ROS-Producing Enzymes and ROS/RNS Production}

The NADPH oxidase enzyme family is an additional source of ROS in HCV-infected cells. This enzyme group consists of seven transmembrane enzymes that participate in electron transport from the membranes and thus produce superoxide anion or $\mathrm{H}_{2} \mathrm{O}_{2}{ }^{[81]}$ Studies in $\mathrm{CHC}$ patients have shown that levels of some defense enzymes such as heme oxygenase (HO-1) ${ }^{[82]}$ and thioredoxin (Trx) ${ }^{[83]}$ are increased. It has also been found that $\mathrm{HCV}$-mediated infections are also a threat to the body's antioxidant systems. On the other hand, researchers detected decreased levels of manyother antioxidant defense enzymes, such as manganeseor $\mathrm{Cu} / \mathrm{Zn}$ superoxide dismutase (SOD), glutathione reductase, and glutathione peroxidase, in the peripheralblood of the patients of $\mathrm{CHC}{ }^{[76,84]}$ although an increase was also reported. ${ }^{[5]}$

\section{Myeloperoxidase}

$\mathrm{MpO}$ is a multifunctionalenzyme involved in both host defense and tissuedamage at inflammatory sites. It produces notonly oxidative equivalents, but contributes also tothe regulation in general response to invading microorganisms. ${ }^{[45]}$ It has been known that $\mathrm{HCV}$ infection is to causes autophagy, and OSand alter $\mathrm{Ca}^{+2}$ 
signaling. For this reason, it is thought that it changes mt structure and functions. ${ }^{[86]}$ Overall, there is evidence that several $\mathrm{HCV}$ proteins directly interact with mitochondria in hepatocytes and alter their function in metabolism, redox balance, ROS scavenging and apoptosis.Nevertheless, the underlying molecular mechanisms of physical interactions reflect how these interactions translate into changing $\mathrm{mt}$ functions and the role of altered mt functions in the viral life cycle and the pathogenesis associated with chronic hepatitis $\mathrm{C}$ are still not fully understood.In our study plasma MPO levels were significantly lower in the CHC patients than the controls $(\mathrm{p}<0.001)$. However Spearman's correlationanalysis showed no significant correlation betweenplasma MPO with viral load (HBVDNAand HCV-RNA), fibrosis score and HAI in patient group $(\mathrm{p}>0.05) .{ }^{[23]}$ Bekhett et al. reported that tissue MPO activity increases significantly in patients with $\mathrm{CVH}-\mathrm{C}$ than the controls, whereas plasma MPO activity does not. ${ }^{[87]}$ Do Carmo et al has found that patients infected by HCV with HCC had higher MPO plasma levels than patients without HCC. MPO levels in patients with HCC have been found approximately three fold more often than patients with chronic HCV or severe fibrosisThese study results support the idea that MPO might have a role in the HCC development [88]

\section{HCV and Antioxidants}

It is known that ROS / RNS plays a role in the onset and progression of the disease and its malignant transformation in patients with hepatitis C.However, the results of studies in which antioxidants are used in therapy of animals and of patients with $\mathrm{HCV}$ are contradictory.Researchers have reported that antioxidants may be employed in 4 different ways 1) to impair in HCV replication 2) to improveliver enzyme levels, 3) to protect against liver cell damageand 4) to render interferon anti-viral therapy more effective.HCV induces OS via several molecular pathways, for example mitochondrial damage and altered metal homeostasis; It is difficult to think of an antioxidant approach with such a wide spectrum of action. Antioxidants such as N-acetylcysteine (NAC), vitamin $\mathrm{E}$, or ascorbic acid, when used alone, have been shown to improve liver damage in patients with $\mathrm{HCV}$ but not affect HCV titres. ${ }^{[88]}$ It has been shown to exhibit reduced levels of GSH and other antioxidants as well as reduced total antioxidant activity in blood and liver biopsies in a large proportion of $\mathrm{CHC}$

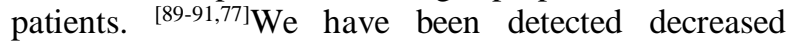
levels of GSH and TAS in blood of CHC patients[49].Decreased GSH may be a consequence of liver damage.Studies have shown that GSH levels in liver and circulation of patients with chronic $\mathrm{HCV}$ cirrhosis are reduced. ${ }^{[80]}$ Proteomic analyzes revealed an upregulation of antioxidant enzymes in the early phase (F1 to F3), but not in the late stages of fibrosis. [92] It has been reported that low catalase and SOD activity and elevated lipid peroxidation levels in chronic $\mathrm{C}$ hepatitis patients indicate deficient antioxidant defense. ${ }^{[53]}$ It has been also displayed decreased levels of antioxidant defense enzymes such as SOD, glutathione reductase, catalase and glutathione peroxidase were also often found in blood of $\mathrm{CHC}$ patient. ${ }^{[49,76,84]}$ Larrea et al has found that expression of the same enzymes was not altered in liver of the same patients. [93] Due to the role of OS in $\mathrm{HCV}$ pathogenesis, antioxidants have been proposed to treat $\mathrm{HCV}$ patients. For example, in a clinical trial, normalization of liver enzymes was observed in $44 \%$ of chronic $\mathrm{HCV}$ patients with elevated pretreatment levels, using a combination antioxidant therapy. In addition histological improvement was also noted in $36.1 \%$ of the patients. ${ }^{[72]}$ However, it is not known exactly how the increased ROS / RNS affects HCV replication. New in vitro cell culture studies supporting the entire life cycle of $\mathrm{HCV}$ are thought to help clarify the complex relationship between OS, $\mathrm{HCV}$, and pathogenesis. In another study decrease in viral load with improvement in liver enzymes and histology was detected in patients receiving oral and intravenous combined antioxidant treatment. ${ }^{[92]}$ Although the results of these studies demonstrate the beneficial effects of antioxidants further studies are needed to properly elucidate the types, amounts, and routes of antioxidant drug administration that are most appropriate. We believe that this antiviral therapeutic strategy should not be overlooked, despite the low efficacy achieved using antioxidant therapies. Continued research is also needed in the areas of antioxidant therapy, to assess the effect of OS on the disease and thus the potential of antioxidant treatment in the attenuation of disease progression.

\section{DISCUSSION}

A various ROS species are produced as a product of cellular metabolism and play an important role in cell signaling and regulation of cytokine, growth factor and hormoneaction, transcription, ion transport, neuromodulation, immune modulation and apoptosis ${ }^{[94]}$ In particular, it is known that it plays a fundamental role in the normal functioning of the immune system and in the proliferation of $\mathrm{T}$ cells and in immunological defense. ${ }^{\left[{ }^{[5]}\right.}$ There is no doubt that OSplays an importantrole in $\mathrm{HBV}$ pathogenesis, therefore, the combination of various mechanisms can produce new solutions to combating the $\mathrm{OS}$ in $\mathrm{HBV}$ infection. 
Although the presence of OS in chronic hepatitis $\mathrm{C}$ and the ability of multiple viral proteins and replicons to produce ROS have been clearly establishedthe contribution of OS to pathogenesis is still unclear.Activated Kupffer cells stimulate hepatic stellate cells to release cytokines and chemokines and promote liver fibrogenesis. Kupffer cells also release reactive oxygen species, nitric oxide and chemotactic proteins, which stimulate hepatocyte damage and increase inflammatory response. ${ }^{[96]}$ NADPH oxidase enzyme can stimulate the production of ROS in hepatic stellate cells, macrophages and hepatocytes. This OS on the hepatocytes can damage deoxyribonucleic acid (DNA), induceapoptosis, promote the expression of pro-inflammatorygenes, enhance fibrogenesis, and possibly trigger malignant transformation. ${ }^{[97]}$ Inducible nitric oxide synthase (iNOS) may increase hepatocyte toxicity by increasing nitric oxide production, and the nuclear factor kappa-light chain enhancer of activated B cells (NF-kB) can regulate iNOS production and OS. ${ }^{[98]}$ As a net result of these various interactive cellular and molecular mechanisms, tissue damage continues and increases the accumulation of extracellular matrix

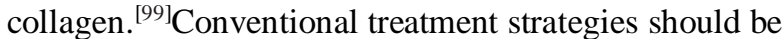
modified to focus on the prevention of hepatic fibrosis and these changes should provide rapid viral clearance and quick complete suppression in the liver inflammation. ${ }^{[99]}$ Even if the cell cytoplasm appears healthy, the cells may be under OS, so conventional methods used to determine OSmust be re-evaluated. Most importantly, solutions must be permanent.

\section{CONCLUSION}

The role of OSin chronic hepatitis triggered liver damage is an important area of research, particularly because that information could be of major therapeutic value in protecting the liver.In the form of ROS and RNS, this OScan damage all of the cells present in the liver, including hepatocytes, Kupffer cells, stellate cells, and endothelial cells, by induction of inflammation, ischemia, fibrosis, necrosis, apoptosis, or malignant transformation through damage to lipids, proteins, and/or DNA.Despite the common OS in hepatitis B, antioxidant therapy is not always considered a treatment strategy, because if antioxidants are not used at the right time and in the right combination they can act like prooxidants. For this reason, large-scale studies will be needed to determine appropriate antioxidant treatments. Natural compounds are known to be potent antioxidants, and some are able to bind $\mathrm{Cu}$ and $\mathrm{Fe}$ and thus control redox potentials. It is known that OSplays an important role in the pathogenesis of $\mathrm{HCV}$, therefore the combination of various mechanisms described in studies can be used to obtain new solutions of OSin HCV infection.OS biomarkers (lipid peroxidation, DNA damage, some protein isolation / expression) help to define a physiological state over time. Measurement of biomarkers allows for the elucidation of the presence of oxidative stress, but does not indicate the cause of this stress. The presence of OS may suggest causality, but using biomarkers alone may lead to only a correlation, not causality.A few of the studies mentioned in this review indicated that there is a correlation between OS markers and liver pathology. Causality can be deduced from these results, but not as proven.As the basic information about the role of OS in the development of the disease and the underlying mechanisms of ROS-related cell toxicity continues to emerge these findings will provide guidance for more rational antioxidant therapeutic approaches.

\section{REFERENCES}

1. Paracha UZ, Fatima $K$, Alqahtani $M$, Chaudhary A,Abuzenadah A,Damanhouri G, et al. Oxidative stress and hepatitis C virus. Virol J. 2013; 10: 251-60

2. Thanan R, Oikawa S, Hiraku Y, Ohnishi S, Ma N, Pinlaor S, et al. Oxidative Stress and Its Significant Roles in Neurodegenerative Diseases and Cancer. Int J Molecul Sci 2014; 16(1): 193217.

3. Cai Z, Yan LJ. Protein Oxidative Modifications: Beneficial Roles in Disease and Health. J Biochem Pharmacol Res. 2013;1(1):15-26

4. Ramírez A, Vázquez-Sánchez AY, CarriónRobalino N, Camacho J. Ion Channels and Oxidative Stress as a Potential Link for the Diagnosis or Treatment of Liver Diseases. Oxid Med Cell Longev. 2016;2(1):12

5. Mari M, Colell A, Morales A, Von Montfort C, GarciaRuiz C, and Fernandez-Checa JC. Redox control of liver function in health and disease. Antioxidants and Redox Signaling 2010; 12 (11): 1295-1331. [6] Sies H. Oxidative stress: introductory remarks, in Oxidative Stress, Academic Press, London, UK, 1985: 1-8.

6. Uttara B, Singh AV, Zamboni P, and Mahajan RT. Oxidative stress and neurodegenerative diseases: a review of upstream and downstream antioxidant therapeutic options, Curr Neuropharmacol 2009; 7 ( 1): 65-74.

7. Henchcliffe $\mathrm{C}$ and Beal MF. Mitochondrial biology and oxidative stress in Parkinson disease pathogenesis. Nat Clin Pract Neurol. 2008; 4 (11): 600-9. 
8. Droge $\mathrm{W}$ and Schipper HM. Oxidative stress and aberrant signaling in aging and cognitive decline. Aging Cell. 2007; 6 (3): 361-70.

9. Hutcheson $\mathrm{R}$ and Rocic $\mathrm{P}$. The metabolic syndrome, oxidative stress, environment, and cardiovascular disease: the great exploration. Exp Diabetes Res. 2012; 1(2):87

10. Can M, Guven B, Bektas S, and Arikan I. Oxidative stres and apoptosis in preeclampsia, Tissue and Cell. 2014; 46(6): 477-81.

11. El-Serag HB. Hepatocellular carcinoma and hepatitis C in the United States. Hepatology. 2002; 36 (1): 74-83.

12. Higgs MR, Chouteau $P$ and Lerat H. Liver let die': oxidative DNA damage and hepatotropic viruses. Journal of General Virology 2014; 95: 991-1004.

13. Gitler C, Danon A. Cellular implications of redox signaling. United Kingdom: Imperial College Press; 2003.

14. Choi $\mathbf{J}$ and James $\mathrm{Ou} \mathrm{JH}$. Mechanisms of Liver Injury. III. Oxidative stress in the pathogenesis of hepatitis $\mathrm{C}$ virus. Am J Physiol Gastrointest Liver Physiol 2006; 290: 847-851.

15. Wheeler M.D, Kono H, Yin M, Rusyn I, Froh M, Connor $\mathrm{HD}$, et al. Delivery of the $\mathrm{Cu} / \mathrm{Zn}$ superoxide dismutase gene with adenovirus reduces alcohol-induced liver injury in rats. Gastroenterology 2001;120: 1941-50

16. Zimmerman HJ, Ishak KG. Hepatic injury due to drugs and toxins. In: MacSween RNM, Anthony PP, Scheuer PJ, Burt AD, Portman BC editors. Pathology of the Liver, third ed. Churchill Livingstone, Edinburgh, 1994 pp. 563-633.

17. SMand ShowrakiA.Hepatitis B and its Relationship With Oxidative Stress. Hepat Mon. 2016; 16(9): e37973.

18. Halegoua-De Marzio D, Hann HW. Then and now: the progress in hepatitis B treatment over the past 20 years. World J Gastroenterol. 2014; 20(2):401-13.

19. Weismann D, Hartvigsen $K$, Lauer $\quad N$, Bennett KL, Scholl HP, Charbel Issa P, et al.Complement factor $\mathrm{H}$ binds malondialdehyde epitopes and protects from oxidative stress. JNature. 2011 5;478 (7367): 76-81.

20. Sen V, Uluca U, Ece A, Kaplan I, Bozkurt F, Aktar F, et al. Serum prolidase activity and oxidant-antioxidant status in children with chronic hepatitis B virus infection. Ital J Pediatr. 2014;40: 95-98.

21. Acar A, Gorenek L, Aydin A, Eyigun CP, Eken A, Sayal A, et al. Investigation of oxidative stress and antioxidant defense in patients with hepatitis $\mathrm{B}$ virus infection and the effect of interferon-alpha plus lamivudine combination therapy on oxidative stress. Mikrobiyol Bul. 2009;43(3):411-23.

22. Namiduru ES, Namiduru $M$, Tarakcioglu $M$, Tanriverdi M. Levels of malondialdehyde, myeloperoxidase and nitrotyrosine in patients with chronic viral hepatitis B and C. Adv Clin Exp Med. 2012;21(1):47-53.

23. Demirdag K, Yilmaz S, Ozdarendeli A, Ozden M, Kalkan A, Kilic SS. Levels of plasma malondialdehyde and erythrocyte antioxidant enzyme activities in patients with chronic hepatitis B. Hepatogastroenterology. 2003;50(51):766-70.

24. Kundu D, Roy A, Mandal T, Bandyopadhyay U, Ghosh E, Ray D. Oxidative stress in alcoholic and viral hepatitis. N Am J Med Sci.2012;4(9):412-5.

25. Tasdelen Fisgin N, Aydin BK, Sarikaya H, Tanyel E, Esen S, Sunbul M, et al. Oxidative stress and antioxidant defense in patients with chronic hepatitis B. Clin Lab. 2012;58(3-4):273-80.

26. Mahdy KA, Abd-El-Shaheed A, Khadr ME, ElShamy KA. Antioxidant status and lipid peroxidation activity in evaluating hepatocellular damage in children. East Mediterr Health J. 2009; 15(4): 842-52.

27. Severi T, Ying C, Vermeesch JR, Cassiman D, Cnops L, Verslype C, et al. Hepatitis B virus replication causes oxidative stress in HepAD38 liver cells. Mol Cell Biochem. 2006; 290(1-2):79_ 85.

28. Dalle-Donne I, Giustarini D, Colombo R, Rossi R, Milzani A. Protein carbonylation in human diseases. Trends Mol Med. 2003;9(4):169-76.

29. Kettle AJ. Detection of 3-chlorotyrosine in proteins exposed to neutrophil oxidants. Methods Enzymol. 1999; 300: 111-20.

30. Meng LZ, Gao AW, Bian JF, Han LJ, Chen H. Study on Correlation between Oxidationantioxidation and Chronic Hepatitis Viral B. Occupation Health. 2010; 23.

31. Garcia-Monzon C, Majano PL, Zubia I, Sanz P, Apolinario A, MorenoOtero R. Intrahepatic accumulation of nitrotyrosine in chronic viral hepatitis is associated with histological severity of liver disease. J Hepatol. 2000;32(2):331-8.

32. Popadiuk S, Liberek A, Korzon M, Renke J, Wozniak M. Free radical reactions and activity of antioxidant barrier in children with chronic hepatitis B. Med Wieku Rozwoj. 2004;8(2):395402.

33. Poungpairoj P, Whongsiri P, Suwannasin S, Khlaiphuengsin A, Tangkijvanich P, Boonla C. Increased Oxidative Stress and RUNX3 Hypermethylation in Patients with Hepatitis B Virus-Associated Hepatocellular Carcinoma 


(HCC) and Induction of RUNX3
Hypermethylation by Reactive Oxygen Species in HCC Cells. Asian Pac J Cancer Prev.2015;16(13):5343-8.

34. Olinski R, Rozalski R, Gackowski D, Foksinski M, Siomek A, Cooke MS. Urinary measurement of 8-OxodG, 8-OxoGua, and 5HMUra: a noninvasive assessment of oxidative damage to DNA. Antioxidants Redox Signal. 2006;8(5-6):1011-9.

35. Shimoda R, Nagashima $M$, Sakamoto $M$, Yamaguchi N, Hirohashi S, Yokota J, et al. Increased formation of oxidative DNA damage, 8hydroxydeoxyguanosine, in human livers with chronic hepatitis. Cancer Res. 1994;54(12):31712.

36. Piciocchi M, Cardin R, Cillo U, Vitale A, Cappon A, Mescoli C, et al. Differential timing of oxidative DNA damage and telomere shortening in hepatitis C and B virus-related liver carcinogenesis. Transl Res. 2016;168:122-33.

37. Kitada T, Seki S, Iwai S, Yamada T, Sakaguchi H, Wakasa K. In situ detection of oxidative DNA damage, 8- hydroxydeoxyguanosine, in chronic human liver disease. J Hepatol. 2001;35(5):613-8.

38. Ishizakai M, Yoshida K, Nishimoto N, Saleh AM, Ishii $\mathrm{C}$, Handa $\mathrm{H}$, et al. [Urinary 8-hydroxy-2'deoxyguanosin $(8-\mathrm{OHdG})$ in patients with chronic liver diseases]. Rinsho Byori. 2004;52(9):732-6.

39. Fujita N, Sugimoto R, Ma N, Tanaka H, Iwasa M, Kobayashi Y, et al. Comparison of hepatic oxidative DNA damage in patients with chronic hepatitis B and C. J Viral Hepat. 2008;15(7):498507.

40. Bhargava A, Khan S, Panwar H, Pathak N, Punde RP, Varshney S, et al. Occult hepatitis B virus infection with low viremia induces DNA damage, apoptosis and oxidative stress in peripheral blood lymphocytes. Virus Res. 2010;153(1):143-50.

41. Guler SA, Tolun FI, Ucmak H, Haskaya G, Yavuz M, Yavuz M. Relationship between antioxidant capacity and oxidative stress in patients with chronic hepatitis B. Advance Laboratory Med Int. 2014;4(1):17-25

42. Tsai SM, Lin SK, Lee KT, Hsiao JK, Huang JC, $\mathrm{Wu} \mathrm{SH}$, et al. Evaluation of redox statuses in patients with hepatitis B virus-associated hepatocellular carcinoma. Ann Clin Biochem. 2009;46(Pt 5):394-400.

43. Nagoev BS, Abidov MT, Ivanova MR. LPO and free-radical oxidation parameters in patients with acute viral hepatitis. Bull Exp Biol Med. 2002;134(6):557-8.
44. Arnhold J. Properties, functions, and secretion of human myeloperoxidase. Biochemistry (Mosc) 2004, 69, 4-9.

45. Mohamadkhani A, Jazii FR, Sayehmiri K, JafariNejad S, MontaserKouhsari L, Poustchi H, et al. Plasma myeloperoxidase activity and apolipoprotein A-1 expression in chronic hepatitis B patients. Arch Iran Med. 2011;14(4):254-8.

46. Ha HL, Shin HJ, Feitelson MA, Yu DY. Oxidative stress and antioxidants in hepatic pathogenesis.World J Gastroenterol 2010 28; 16(48): 6035-6043

47. Valko M, Leibfritz D, Moncol J, Cronin MT, Mazur M, Telser J. Free radicals and antioxidants in normal physiological functions and human disease. Int J Biochem Cell Biol. 2007;39(1):4484.

48. Namıduru ES, Namıduru M, Tarakçıŏlu M, Toy A. Antioxidant defence in patients with chronic viral hepatitis B and C type. Clin. Lab. 2010; 56: 207-213.

49. Pal S, Bose M, Paul S. A comparative study of oxidative stress parameters in hepatitis $b$ virus infection \& alcoholic hepatitis. J Drug Delivery Therapeutic. 2013;3(5):94-8.

50. Kulinskii VI, Leonova ZA, Kolesnichenko LS, Malov IV, Danilov Iu A. Glutathione system in erythrocytes and plasma in viral hepatitis. Biomed Khim. 2007;53(1):91-8.

51. Lin CC, Liu WH, Wang ZH, Yin MC. Vitamins B status and antioxidative defense in patients with chronic hepatitis B or hepatitis $\mathrm{C}$ virus infection. Eur J Nutr. 2011;50(7):499-506.

52. Chrobot AM, Szaflarska-Szczepanik A, Drewa G. Antioxidant defense in children with chronic viral hepatitis B and C. Med Sci Monit. 2000;6(4):7138.

53. Shaban NZ, Salem HH, Elsadany MA, Ali BA, Hassona EM, AK F. Alterations in lipid peroxidation and antioxidants in patients' with different stages of hepatitis b virus infection in Egypt. Life Sci J. 2014.

54. Irshad M, Chaudhuri PS, Joshi YK. Superoxide dismutase and total anti-oxidant levels in various forms of liver diseases. Hepatol Res.2002;23(3):178-84.

55. Duygu F, Karsen H, Aksoy N, Taskin A. Relationship of oxidative stress in hepatitis B infection activity with HBV DNA and fibrosis. Ann Lab Med. 2012;32(2):113-8.

56. Karsen H, Binici I, Sunnetcioglu M, Baran AI, Ceylan MR, Selek S, et al. Association of paraoxonase activity and atherosclerosis in 
patients with chronic hepatitis B. Afr Health Sci. 2012;12(2):114-8.

57. Moulas A, Noulas A, Makri E, Papadamou G, Bonanou-Tzedaki S, Dalekos G. Total antioxidant status and erythrocyte superoxide dismutase activity in patients with chronic hepatitis B and C. European J Inflam. 2004;2(2):77-84.

58. Fan XP, Wang K, Liu Y, Wang JF. Plasma $\alpha-$ Tocopherol is Negatively Correlated with Hepatocyte Apoptosis in Chronic Hepatitis B Patients. Internal Med. 2009;48(18):1585-93.

59. Ivanov AV, Bartosch $B$, Smirnova OA, Isaguliants MG, Kochetkov SN. HCV and oxidative stress in the liver.Viruses. 2013;5(2):439-69.

60. Guidotti LG, Chisari FV. Immunobiology and pathogenesis of viral hepatitis Annu Rev Pathol. 2006;1: 23-61.

61. Vasallo C, Gastaminza P. Cellular stress responses in hepatitis $\mathrm{C}$ virus infection: Mastering a twoedged sword.Virus Res. 2015 Nov 2;209:100-17.

62. Farinati F, Cardin R, De Maria N, Della Libera G, Marafin C, Lecis E, et al..Iron storage, lipid peroxidation and glutathione turnover in chronic anti-HCV positive hepatitis. J Hepatol. 1995; 22(4):449-56.

63. Wang $\mathrm{T}$, Weinman SA. Interactions Between Hepatitis C Virus and Mitochondria: Impact on Pathogenesis and Innate Immunity. Curr Pathobiol Rep. 2013;1(3):179-187.

64. Knolle PA, Gerken G. Local control of the immune response in the liver. Immunol. Rev. 2000; 174: 21-34.

65. Yen HH, Shih KL, Lin TT, Su WW, Soon MS, Liu CS. Decreased mitochondrial deoxyribonucleic acid and increased oxidative damage in chronic hepatitis C. World J Gastroenterol. 2012; 18(36):5084-9.

66. Chan SW. Establishment of chronic hepatitis C virus infection: translational evasion of oxidative defence. World J Gastroenterol. 2014; 2( 20): 2785-2800.

67. Malik AN, Czajka A. Is mitochondrial DNA content a potential biomarker of mitochondrial dysfunction? Mitochondrion 2013; 13: 481-492

68. Wang $T$ and Weinman SA. Causes and consequences of mitochondrial reactive oxygen species generation in hepatitis C. J Gastroenterol Hepatol. 2016; 21: 34-37

69. Qadri I, Iwahashi M, Capasso JM, Hopken MW, Flores S, Schaack J, et al. Induced oxidative stress and activated expression of manganese superoxide dismutase during hepatitis $\mathrm{C}$ virus replication: role of JNK, p38 MAPK and AP-1. Biochem J 2004; 378: $919-928$
70. Farias MS, Budni $P$, Ribeiro CM, Parisotto EB, Santos CE, Dias JF, et al. Antioxidant supplementation attenuates oxidative stress in chronic hepatitis $\mathrm{C}$ patients. Gastroenterol Hepatol 2012; 35: 386-394.

71. Gane EJ, Weilert F, Orr DW, Keogh GF, Gibson M, Lockhart MM, et al. The mitochondria-targeted anti-oxidant mitoquinone decreases liver damage in a phase II study of hepatitis C patients. Liver Int 2010; 30: 1019-1026.

72. Melhem A, Stern M, Shibolet $O$, Israeli $E$, Ackerman Z, Pappo O, et al. Treatment of chronic hepatitis $\mathrm{C}$ virus infection via antioxidants: results of a phase I clinical trial. J Clin Gastroenterol 2005; 39: 737-742.

73. Vendemiale G, Grattagliano I, Caruso ML, Serviddio G, Valentini AM, Pirrelli M, et al. Increased oxidative stress in dimethylnitrosamineinduced liver fibrosis in the rat: effect of $\mathrm{N}$ acetylcysteine and interferon-alpha. Toxicol Appl Pharmacol. 2001;175(2):130-9.

74. Venturini D, Simão AN, Barbosa DS, Lavado EL, Narciso VE, Dichi I,et al. Increased oxidative stress, decreased total antioxidant capacity, and iron overload in untreated patients with chronic hepatitis C.Dig Dis Sci. 2010;55(4):1120-7.

75. De Maria N, Colantoni A, Fagiuoli S, Liu GJ, Rogers BK, Farinati F, et al. Association between reactive oxygen species and disease activity in chronic hepatitis C.Free Radic Biol Med. 1996;21(3):291-5

76. Bhargava A, Raghuram GV, Pathak N, Varshney $\mathrm{S}$, Jatawa SK, Jain D,et al. Occult hepatitis $\mathrm{C}$ virus elicits mitochondrial oxidative stress in lymphocytes and triggers PI3-kinase-mediated DNA damage response. Free Radic. Biol. Med. 2011;51: 1806-1814.

77. Bessa SS, Mohamed Ali EM, Abd El-Wahab Ael $\mathrm{S}$, Nor El-Din SA. Heme oxygenase-1 mRNA expression in egyptian patients with chronic liver disease. Hepat. Mon. 2012;12: 278-285.

78. Cardin R, Saccoccio G, Masutti F, Bellentani S, Farinati F, Tiribelli C. DNA oxidative damage in leukocytes correlates with the severity of HCVrelated liver disease: Validation in an open population study. J. Hepatol. 2001;34: 587-592.

79. Liu MC, Yasuda S, Idell S. Sulfation of nitrotyrosine: Biochemistry and Functional Implications. IUBMB life 2007; 59: 622-627.

80. Loguercio $C$ and Federico $A$. Oxidative stress in viral and alcoholic hepatitis. Free Radic. Biol. Med. 2003; 34( 1): 1-10.

81. Takac I, Schroder K, Zhang L, Lardy B, Anilkumar N, Lambeth JD, et al. The E-loop is 
involved in hydrogen peroxide formation by the NADPH oxidase Nox4. J Biol Chem 2011; 286: 13304-13.

82. Sumida $Y$, Nakashima $T$, Yoh $T$, Nakajima $Y$, Ishikawa $\mathrm{H}$, Mitsuyoshi $\mathrm{H}$, et al. Serum thioredoxin levels as an indicator of oxidative stress in patients with hepatitis $\mathrm{C}$ virus infection. $\mathrm{J}$ Hepatol 2000; 33(4):616-622.

83. Fujinaga $H$, Tsutsumi $T$, Yotsuyanagi $H$, Moriya $\mathrm{K}$, Koike K: Hepatocarcinogenesis in hepatitis C: HCV shrewdly exacerbates oxidative stress by modulating both production and scavenging of reactive oxygen species. Oncology 2011; 81(Suppl 1):11-17.

84. Osman HG, Gabr OM, Lotfy S, Gabr S. Serum levels of bcl-2 and cellular oxidative stress in patients with viral hepatitis. Indian $\mathbf{J}$ Med Microbiol 2007, 25(4):323-329.

85. Merquiol E, Uzi D, Mueller T, Goldenberg D, Nahmias Y, Xavier RJ, et al. HCV causes chronic endoplasmic reticulum stress leading to adaptation and interference with the unfolded protein response. PLoS One 2011; 6: e24660

86. Bekheet IW, Madkour ME, Ghaffar NA, Nosseir MMF, Moussa MM, Ibraheim RA, et al. The role of Myeloperoxidase in Hepatitis C Virus Infection and Associated liver Cirrhosis. Open Trop Med J 2009; 2: 1-7.

87. Do Carmo RF, de Almeida DB, Aroucha DC, Vasconcelos LR, de Moraes AC, de Mendonça Cavalcanti Mdo S, et al. Plasma myeloperoxidase levels correlate with hepatocellular carcinoma in chronic hepatitis C. Human Immunology. 2012; 73: 1127-31.

88. Pawlotsky JM. Treatment of chronic hepatitis C: current and future. Curr Top Microbiol Immunol. 2013;369:321-42.

89. Look MP, Gerard A, Rao GS, Sudhop T, Fischer $\mathrm{HP}$, Sauerbruch T, et al. Interferon/antioxidant combination therapy for chronic hepatitis $\mathrm{C}-\mathrm{a}$ controlled pilot trial. Antiviral Res. 1999; 43: 113122.

90. Jain SK, Pemberton PW, Smith A, McMahon RF, Burrows PC, Aboutwerat A, et al. Oxidative stress in chronic hepatitis $\mathrm{C}$ : not just a feature of late stage disease. J. Hepatol. 2002;36: 805-811.
91. Diamond DL, Jacobs JM, Paeper B, Proll SC, Gritsenko MA, Carithers RL Jr, et al. Proteomic profiling of human liver biopsies: hepatitis $\mathrm{C}$ virus-induced fibrosis and mitochondrial dysfunction. Hepatology. 2007; 46(3):649-57.

92. Larrea E, Beloqui O, Munoz-Navas MA, Civeira MP, Prieto J. Superoxide dismutase in patients with chronic hepatitis $\mathrm{C}$ virus infection. Free Radic. Biol. Med. 1998; 24: 1235-1241.

93. Gabbay E, Zigmond E, Pappo O, Hemed N, Rowe M, Zabrecky G, et al. Antioxidant therapy for chronic hepatitis $\mathrm{C}$ after failure of interferon: results of phase II randomized, double-blind placebo controlled clinical trial. World J Gastroenterol. 2007;13(40):5317-23.

94. Devadas S, Zaritskaya L, Rhee SG, Oberley L, Williams MS: Discrete generation of superoxide and hydrogen peroxide by $\mathrm{T}$ cell receptor stimulation: selective regulation of mitogenactivated protein kinase activation and fas ligand expression. J Exp Med 2002; 195(1):59-70.

95. Lee UE, Friedman SL. Mechanisms of hepatic fibrogenesis. Best Pract Res Clin Gastroenterol 2011; 25: 195-206

96. Bhogal RH, Curbishley SM, Weston CJ, Adams DH, Afford SC. Reactive oxygen species mediate human hepatocyte injury during hypoxia/ reoxygenation. Liver Transpl 2010; 16: 1303-1313

97. Tanaka H, Fujita N, Sugimoto R, Urawa N, Horiike S, Kobayashi Y, et al. Hepatic oxidative DNA damage is associated with increased risk for hepatocellular carcinoma in chronic hepatitis $\mathrm{C}$. $\mathrm{Br}$ J Cancer 2008; 98: 580-586.

98. Sanz-Cameno P, Medina J, García-Buey L, García-Sánchez A, Borque MJ, Martín-Vílchez S, et al. Enhanced intrahepatic inducible nitric oxide synthase expression and nitrotyrosine accumulation in primary biliary cirrhosis and autoimmune hepatitis. J Hepatol 2002; 37: 723729.

99. Desmoulière A, Darby I, Costa AM, Raccurt M, Tuchweber B, Sommer P, et al. Extracellular matrix deposition, lysyl oxidase expression, and myofibroblastic differentiation during the initial stages of cholestatic fibrosis in the rat. Lab Invest 1997; 76: 765-778.

Conflict of Interest: None

Source of Support: Nil 